\title{
Implementation of a Multi-cell Approach in the Multi-Physics Calculations of an Aqueous Homogeneous Reactor
}

\author{
D. M. Pérez ${ }^{1 *}$, A. G. Rodríguez ${ }^{1}$, L. H. Pardo 2 , D. Milian P. ${ }^{3}$, D. M. Lorenzo ${ }^{2}$, and C. A. Brayner ${ }^{4}$ \\ ${ }^{1}$ Departamento de Energia Nuclear, Universidade Federal de Pernambuco (UFPE), Cidade Universitária, Avenida \\ Professor Luiz Freire 1000, CEP: 50670-901, Recife, PE, Brasil. \\ ${ }^{2}$ Nuclear Engineering Department, Higher Institute of Technologies and Applied Sciences (InSTEC), University of \\ Havana, Avenida Salvador Allende y Luaces, Quinta de Los Molinos, Plaza de la Revolución, 10400 Havana, Cuba. \\ ${ }^{3}$ Departamento de Energía Renovable y Eficiencia Energética, Cubaenergía, Playa, Habana, Cuba. \\ ${ }^{4}$ Centro Regional de Ciências Nucleares (CRCN-NE/CNEN), Cidade Universitária, Avenida Professor Luiz Freire 200, \\ CEP: 50740-545, Recife, PE, Brasil. \\ E-mail: daniel.milian@ufpe.br, abel.rodriguez@ufpe.br, lhernandez@instec.cu, dmperez@ cubaenergia.cu, \\ dmilian@instec.cu, brayner@cnen.gov.br
}

Received 11 March 2021, Revised 22 November 2021, Accepted 23 November 2021

\begin{abstract}
Nowadays, the Aqueous Homogeneous Reactor (AHR) technology is under study for its use in the production of medical isotopes. This technology has proven to be potentially advantageous for this purpose due to its low cost, small critical mass, inherent passive safety, and simplified fuel handling, processing, and purification characteristics. Among the studies being carried out is computational modeling and simulation, which represents a key technology in the pursuit for improvements in efficiency, safety, and reliability of these systems. This paper aims to expand upon a previous AHR computational model through the implementation of a multi-cell approach for the improvement of the calculations using a methodology for the multi-physics and multi-scale coupling of the neutronic and thermal-hydraulic codes. It was found that these additions to the original model cause a small change to the overall reactor behavior. Thermal-hydraulic parameters such as, average fuel solution temperature and velocity, gas volume fraction and average radiolytic gas bubbles velocity undergo a variation of $0.161{ }^{\circ} \mathrm{C}, 0.0009$ $\mathrm{m} / \mathrm{s}, 0.015 \%$ and $0.0003 \mathrm{~m} / \mathrm{s}$. In contrast, significant local differences were obtained mainly for the fuel solution temperature and radiolytic gas bubbles volume fraction. It was verified that a simplified AHR computational model consisting of a $20^{\circ}$ section of the fuel solution is able to adequately reproduce the results of the full AHR computational model.
\end{abstract}

Keywords: Aqueous homogeneous reactor; radioisotope production; multi-physics; multi-cell approach; MCNP; ANSYS-CFX.

\section{Introduction}

Over the past decade, the supply of ${ }^{99} \mathrm{Mo} /{ }^{99 m} \mathrm{Tc}$ to health care institutions has often been unreliable due to unanticipated and planned shutdowns and extended maintenance periods at some of the main facilities that produce ${ }^{99} \mathrm{Mo}$, many of which are relatively old. As a result, creating extended global shortages. In particular, the 20092010 supply shortages due to unanticipated and planned shutdowns of the main producer reactors (NRU and HFR) and the subsequent limited supply shortages which have continued to occur in 2013,2014, 2015, 2017, 2018 and early 2019. Evidencing the existence of a chronic level of supply shortage in some markets at various periods [1]-[4].

The scientific literature recognizes the use of the Aqueous Homogeneous Reactor (AHR) technology for medical isotopes production as potentially advantageous taking into consideration its low cost, small critical mass, inherent passive safety, and simplified fuel handling, processing, and purification characteristics [5]. However, further studies are needed to confirm that hypothesis and contribute to the development and demonstration of their technical, safety, and economic viability. Considering the lack of experimental facilities (at the beginning of 2021 only two homogeneous liquid fuel experimental reactors were in operation, both in the Russian Federation [6]) and the costs associated with their construction, the use of the computational modeling and simulation represents a key technology in the pursuit for improvements in efficiency, safety, and reliability of these systems.

For several years our research group has worked in the modeling, simulation and behavior prediction of solution reactors, mainly ARGUS type AHRs, through relevant physical parameters. Some of the main tasks carried out by our research group for the not coupled multi-physics modeling and simulation of AHRs were summarized in [7]. In [8], it was presented and discussed a computational model and methodology for the multi-physics and multiscale coupling of the neutronic and thermal-hydraulic codes to predict the steady state operation of a LEU fuel ARGUS type AHR for producing ${ }^{99} \mathrm{Mo}$ to meet the domestic demand of Brazil. The developed methodology allowed the coupling of the computational codes MCNP6 [9] (for the neutronic calculations) and ANSYS-CFX 19 [10] (for the thermalhydraulic assessment) using "home-made" codes for the 
pre-processing and post-processing of the main codes. In addition, validation calculations results were presented using available data of two different operating configurations of the ARGUS reactor, the original HEU configuration used since 1981, and the new LEU configuration after the conversion process during 20122014.

This paper aims to expand upon that previous AHR computational model trough the implementation of a multicell approach for the improvement of the calculations using the methodology for the multi-physics and multi-scale coupling of the neutronic and thermal-hydraulic codes. To fulfill this objective, a simplified AHR computational model was developed, consisting of a $20^{\circ}$ section of the fuel solution. The suitability of that simplified model was tested through comparison with results obtained with the full AHR computational model in [8].

\section{Methodology}

The computational modeling and simulation were carried out using two computational codes, the MCNP6 [9] and ANSYS-CFX 19 [10] for the neutronic and thermalhydraulic calculations, respectively. Additionally, a group of home-made pre- and post-processing codes were used for the handling of the input and output data of the main codes. The multi-physics coupled and parallel calculations were carried out in the computational cluster UFPE-DEN-GER (operating system: Microsoft Windows 64 bit, 64 cores and 152 GB Memory). Neutronic calculations with MCNP6 used a total of 50 million active neutron stories, with 50 inactive stories at the beginning of each calculation step. For the calculations with ANSYS-CFX a convergence criterion of $10^{-6}$ was established for the mass, momentum, energy, and turbulence equations.

\subsection{AHR conceptual design}

In [8], the steady state operation of an ARGUS type AHR conceptual design using LEU fuel (Figure 1) for producing ${ }^{99} \mathrm{Mo}$ was presented and evaluated to meet the estimated Brazilian demand for 2025. That conceptual design was an improved version of previous designs [11] [13]. The main differences of the [8] conceptual design and the previous are in the thermal power and heat removal system used. It was used a thermal power of $50 \mathrm{kWth}$, with which the conceptual design has the capability to produce 246.5 six days Curie of ${ }^{99} \mathrm{Mo}$ in operation cycles of five days (equivalent to more than a third of the estimated Brazilian demand for 2025). The heat removal system was improved to take into consideration the increase in the thermal power, the improvements included increasing the refrigerant mass flow rate, diminish the refrigerant inlet temperature and the addition of a second coiled cooling pipe.

Table 1 shows some of the main parameters that characterize the conceptual design developed at the beginning of the operation. The detailed description of the AHR conceptual design can be found in [8]. The calculational time for this model was five hours for each neutronic calculation with MCNP6 and ten days for the first ANSYS-CFX calculation, and two days for the following ANSYS-CFX iterative calculations steps. In summary, the completion of an iterative coupled calculation had durations of at least twenty days. In summary, the completion of an iterative coupled calculation had durations of at least twenty days. That reason led to the development of a simplified
AHR computational model (omitting the coiled cooling pipe, cooling water and core channels) in this paper, for the ANSYS-CFX calculations. The simplified model, consisting of a $20^{\circ}$ section of the fuel solution, was considered symmetric to reduce computational costs. The completion of an iterative coupled calculation with the simplified model required no more than three days, reducing the calculation time to $15 \%$ of that required by the full AHR computational model.

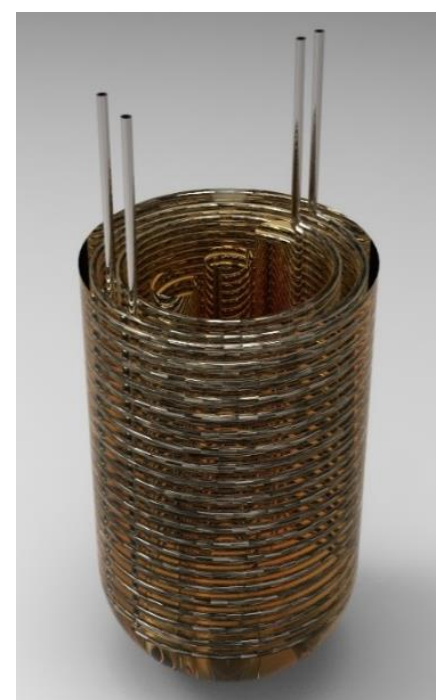

Figure 1. AHR conceptual design.

Table 1. The reactor core parameters.

\begin{tabular}{ll}
\hline Parameter & Value \\
\hline Fuel solution & Uranyl sulfate $\left(\mathrm{UO}_{2} \mathrm{SO}_{4}\right)$ \\
solution \\
${ }^{235} \mathrm{U}$ enrichment $(\%)$ & 19.8 \\
Uranium concentration $(\mathrm{g} /$ liter $)$ & 380 \\
Inner core diameter $(\mathrm{cm})$ & 30.5 \\
Reactor height $(\mathrm{cm})$ & 65.6 \\
Reactor vessel & Stainless steel \\
Vessel thickness $(\mathrm{cm})$ & 0.5 \\
Reflector $($ radial $)$ & Graphite $-60 \mathrm{~cm}$ \\
Solution Density $\left(\mathrm{g} / \mathrm{cm}^{3}\right)$ & 1.4950 \\
Fuel solution height $(\mathrm{cm})$ & 52.92 \\
Amount of ${ }^{235} \mathrm{U}$ in the whole reactor & 2.10 \\
$(\mathrm{~kg})$ & \\
Cold solution volume with no voids & 29.50 \\
(liter) & 50 \\
Thermal Power $(\mathrm{kWth})$ & 1.70 \\
Power density $(\mathrm{kWth} / \mathrm{liter}$ of solution) & less than $90^{\circ} \mathrm{C}$ \\
Operating temperature &
\end{tabular}

\subsection{Implementation of the multi-cell approach and improvements in the coupling methodology}

Although the computational model and methodology previously developed [8] allowed us to obtain results with a higher level of detail and precision than those obtained through neutronic and thermal-hydraulic simulations separately, some possible improvements in the computational model and methodology have been examined in order to bring our results even closer to reality. One of those improvements is the utilization of a multi-cell approach in the MCNP6 model to address the nonuniformity of the fuel solution density along with the reactor height. The necessity of the implementation of the multi-cell approach is reinforced by the results obtained for the conceptual design studied in [8], which it was evidenced a relative difference of approximately $3 \%$ between the average density of the upper and lower zones of the fuel solution. Figure 2 shows the geometrical model of the AHR 
conceptual design on the Visual Editor of the MCNP with and without the multi-cell approach. As can be seen, the fuel solution was divided into 14 axial sections. The division into radial sections was not implemented, considering that previous studies have shown that the fuel solution density variation in the radius is negligible. Figure 3 shows the geometrical model of the AHR conceptual design in the ANSYS SpaceClaim module with and without the multi-cell approach.

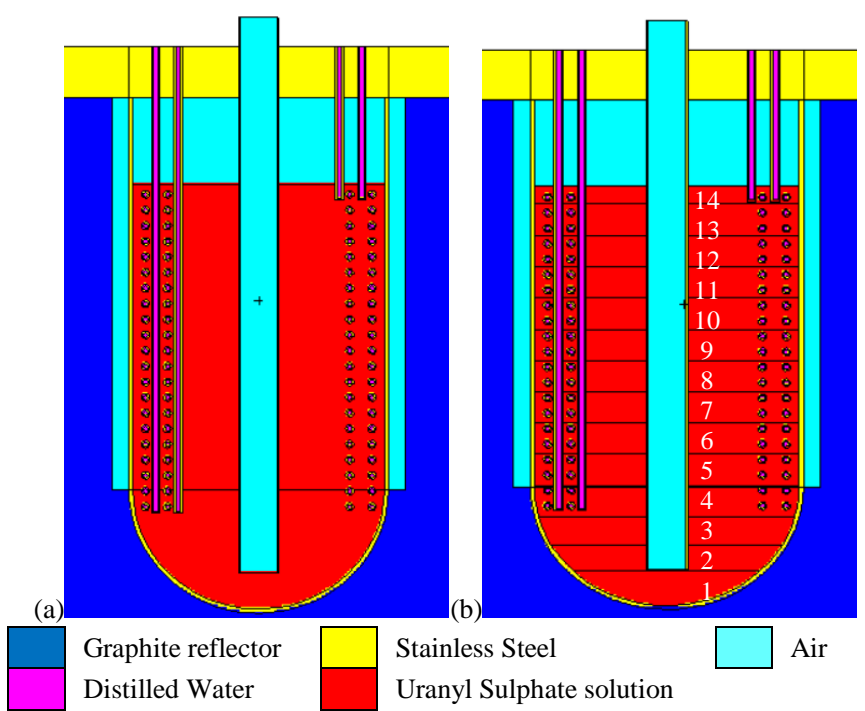

Figure 2. Longitudinal section of the geometrical model of the AHR conceptual design on the Visual Editor of the MCNP with (a) and without (b) the multi-cell approach.

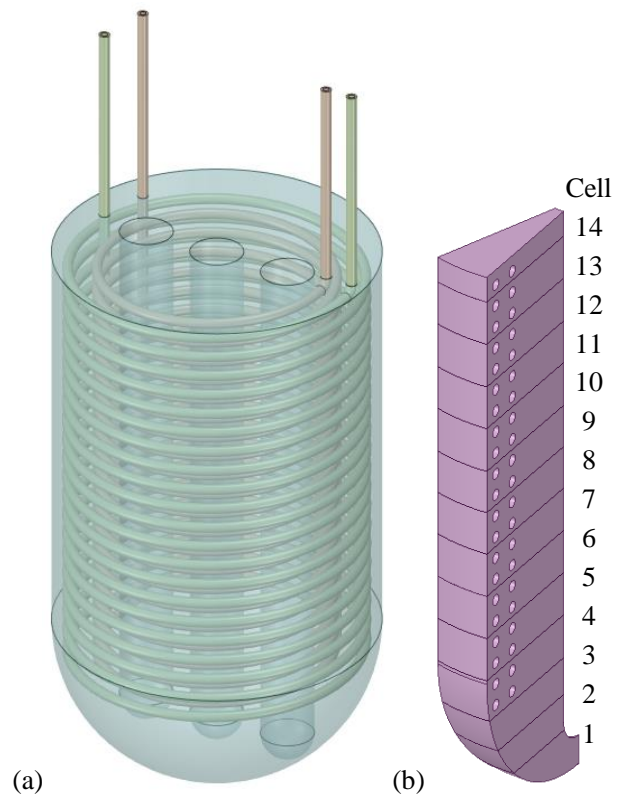

Figure 3. AHR conceptual design in the ANSYS SpaceClaim module with (a) and without (b) the multi-cell approach.

As observed, the geometrical model with the multi-cell approach is constituted only by a $20^{\circ}$ section of the fuel solution. The selection of the $20^{\circ}$ section was made after performing a sensitivity study with six core sections, between $5^{\circ}$ and $30^{\circ}$ (Figure 4 ). In the results and discussion section, the results of the sensitivity study is presented.

The coupling methodology used for the calculations was also modified to take into consideration the multi-cell approach. Now, after each ANSYS-CFX calculation step is rectified the mass density of each fuel solution cell in the
MCNP6 model instead of changing only the global mass density, as it was done in [8]. In [7], [8], [11]-[14] are explained, described and discussed the selection of the computational models, thermal and material properties correlations, boundary conditions, solution parameters, geometrical and material approximations and others modeling related topics.

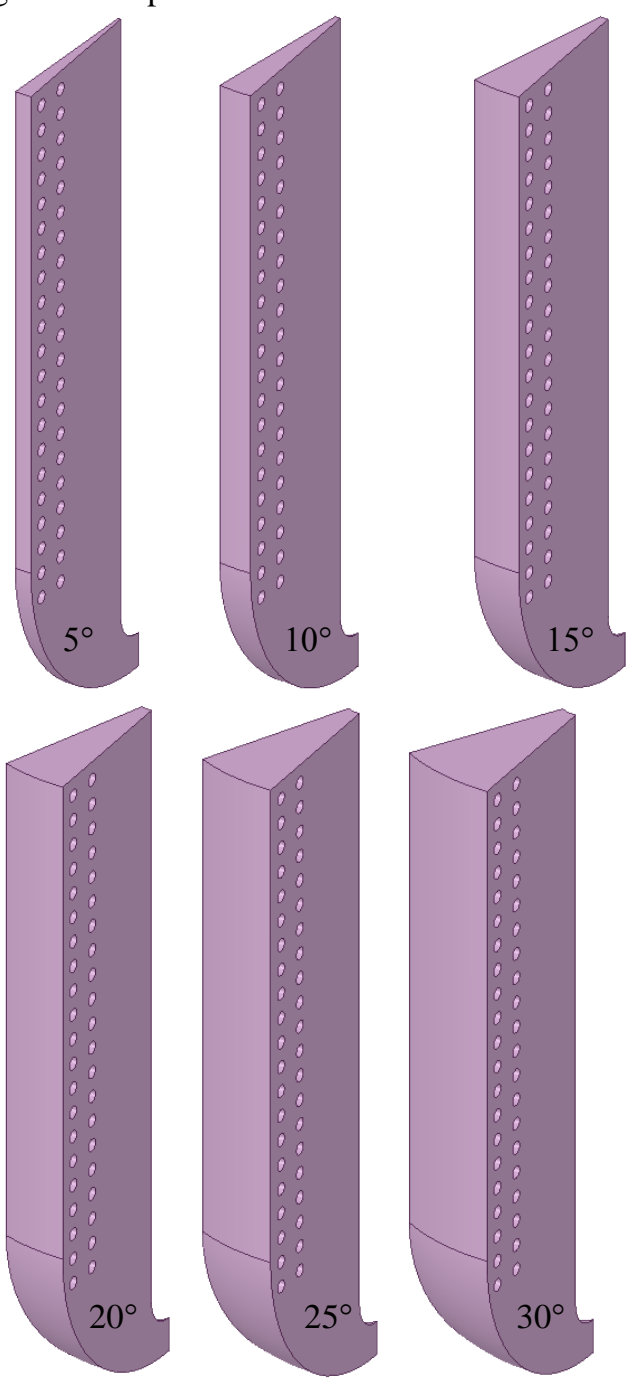

Figure 4. Fuel solution sections in the ANSYS SpaceClaim module.

\section{Results and Discussion \\ 3.1 Mesh independence study}

A mesh independence study was performed to determine the element size for which the results are independent of the mesh used. Various mesh element sizes, in a range of $0.15 \mathrm{~cm}$ to $0.60 \mathrm{~cm}$, were assessed. Table 2 shows the elements sizes studied and the number of nodes and elements generated for the $20^{\circ}$ model.

Table 2. Characteristics of the meshes studied.

\begin{tabular}{cccc}
\hline Mesh ID & Element size $(\mathrm{cm})$ & Elements & Nodes \\
\hline 1 & 0.60 & $283 \mathrm{k}$ & $310 \mathrm{k}$ \\
2 & 0.50 & $300 \mathrm{k}$ & $328 \mathrm{k}$ \\
3 & 0.40 & $323 \mathrm{k}$ & $352 \mathrm{k}$ \\
4 & 0.35 & $349 \mathrm{k}$ & $380 \mathrm{k}$ \\
5 & 0.30 & $391 \mathrm{k}$ & $424 \mathrm{k}$ \\
6 & 0.25 & $463 \mathrm{k}$ & $500 \mathrm{k}$ \\
7 & 0.20 & $604 \mathrm{k}$ & $648 \mathrm{k}$ \\
8 & 0.15 & $1049 \mathrm{k}$ & $1114 \mathrm{k}$ \\
\hline
\end{tabular}


To evaluate the mesh independence was studied the convergence of four fuel solution important parameters (fuel solution average temperature and velocity and radiolytic gas bubbles average volume fraction and velocity). Figures 5 and 6 show the values obtained for those paraments for each mesh. The parameters studied converge below a relative difference of $1 \%$ from mesh 7 (element size $0.20 \mathrm{~cm}$ ) and onwards. Therefore, all simulations with ANSYS CFX will be performed with that element size.

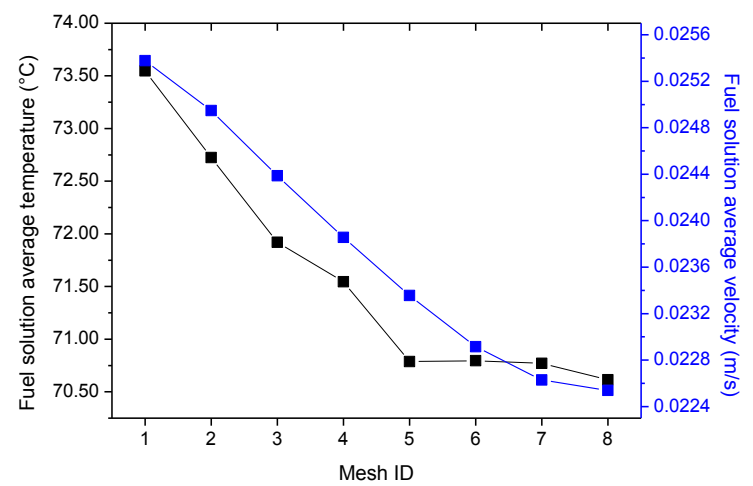

Figure 5. Fuel solution average temperature and velocity for the eight meshes studied.

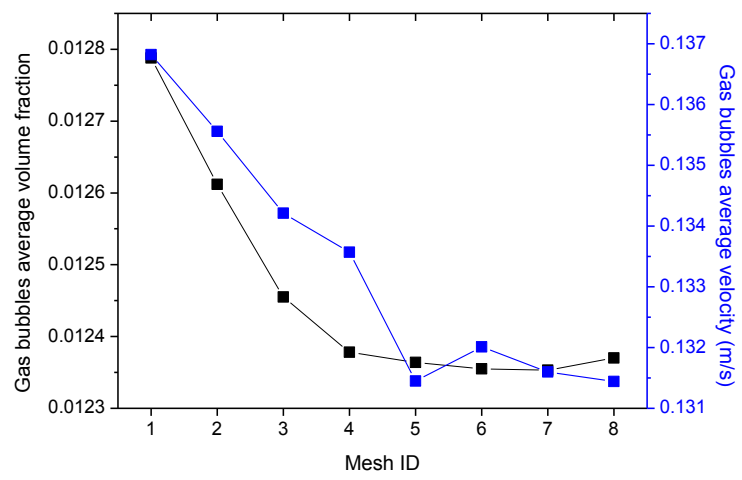

Figure 6. Radiolytic gas bubbles average volume fraction and velocity for the eight meshes studied.

\subsection{Selection and verification of the simplified model}

In order to select a simplified AHR computational model, consisting of only a section of the fuel solution, a sensitivity study with six core sections was carried out between $5^{\circ}$ and $30^{\circ}$. The results of the parameters of interest (fuel solution average temperature and velocity and radiolytic gas bubbles average volume fraction and velocity) obtained from those calculations were compared against the results obtained in [8] for the full AHR computational model.

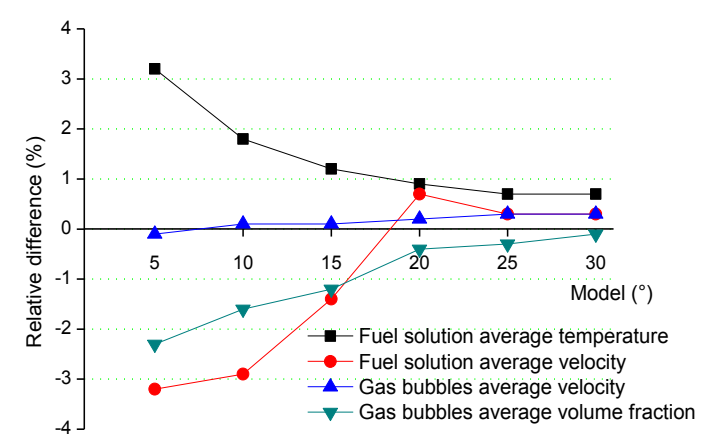

Figure 7. Relative difference in $\%$ for the six sections studied.

Figure 7 shows the evolution of the relative difference in $\%$ of those parameters with the results of the full AHR computational model for the six sections studied. As can be seen, the parameters of interest differ from the parameters obtained for the full AHR computational model in less than $1 \%$ for the $20^{\circ}$ section model and onwards. So, the calculations with the computational methodology and the multi-cell approach will be performed with the $20^{\circ}$ model.

\subsection{Results with the multi-cell approach}

After determining, first, the element size for which the results are independent of the mesh used and second, the simplified AHR computational model consisting of a $20^{\circ}$ section, was applied the computational methodology developed in [8] and improved for this paper for the determination of the steady-state operation of the AHR conceptual design. Figures 8 and 9 show the evolution of the global average thermal-hydraulic parameters selected to monitor the convergence of the coupled iterative calculation during four iterative calculation steps. Step " 0 " corresponds to the results obtained in [8], which were used as an initial approximation for the calculation.

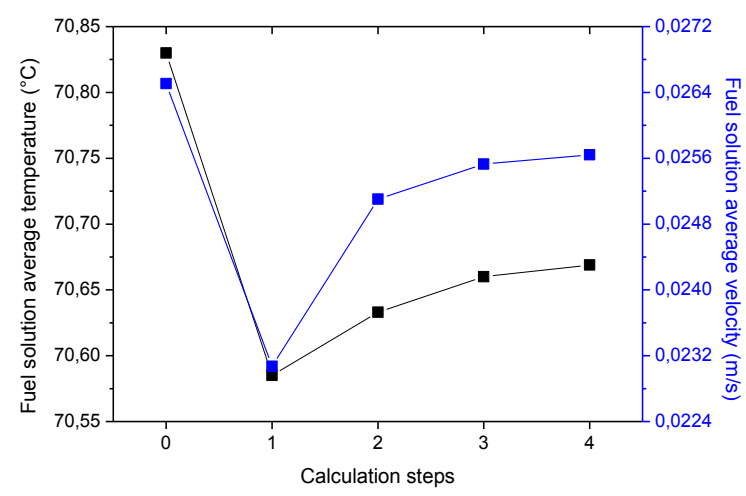

Figure 8. Evolution of the average fuel solution temperature and velocity. 


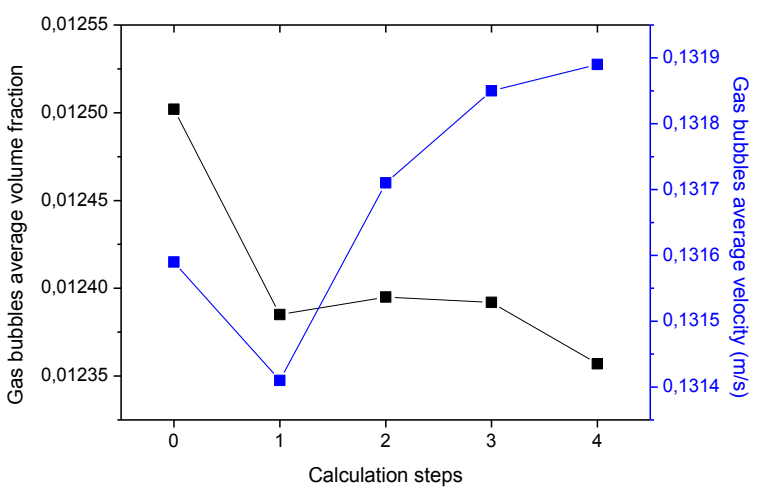

Figure 9. Evolution of the average radiolytic gas volume fraction and velocity.

As expected, considering that an initial approximation in the results of [8] was used, the convergence of the methodology was achieved rapidly in just four calculation steps. After the second calculation step, the fuel solution average temperature and the average radiolytic gas volume fraction and velocity reach the convergence criterion (relative difference less than or equal to $1 \%$ ). The parameter that decisively influenced the convergence of the coupled iterative calculation was the average fuel solution velocity, it is only after four calculation steps that its variation is less than $1 \%$. The convergence of the methodology for each of the 14 cells was also studied, to ensure that convergence is achieved at the cell level. The results obtained for the thermohydraulic parameters of interest, using the average values of each cell, were similar to those obtained with the global averages.

Figures 10 and 11 show the variation in the average fuel solution temperature and radiolytic gas volume fraction for each iterative calculation step, as well as for the initial approximation. As observed, the difference, not only in the profile, but also in absolute value is appreciable throughout the entire core of the AHR conceptual design. In Figure 10 it is observed how after four iterative calculation steps, the fuel solution temperature in the lower zone tends to decrease, while it increases in the upper zone with increasing steps. A similar behavior, only in the opposite direction, was observed for the average radiolytic gas bubbles and fuel solution velocities, which increase in the lower zone and decrease in the upper one with increasing steps. This phenomenon has already been observed in previous investigations, which have verified the importance of the gas bubbles and fuel solution velocities in increasing or decreasing heat transfer and temperature in each region of the reactor [8], [12], [15]. Figure 11 shows the expected behavior for the distribution of gas bubbles in the core. In the lower cells the amount of gas is very low, less than $0.08 \%$ of the mixture for cell "1". With the increase in the height of the core the amount of gas increases, coming to constitute approximately $2.34 \%$ in the top cell. Figure 12 shows the fission induced energy deposition profile in the AHR conceptual design for the model with (Figure 12 (a)) and without (Figure 12 (b)) the multi-cell approach in relative units. At first glance, it does not appear to be significant differences between the two profiles.

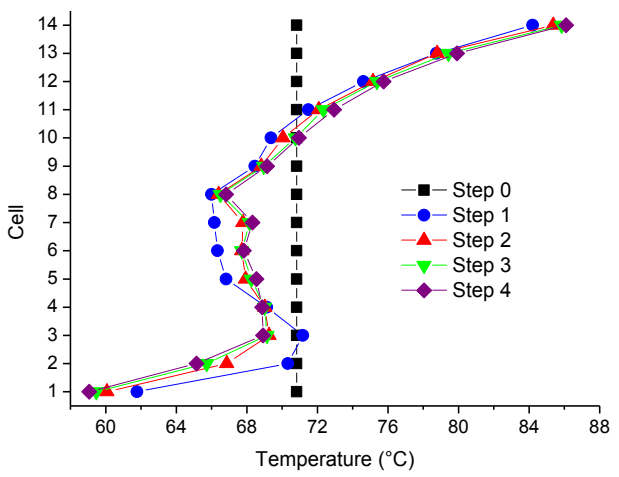

Figure 10. Axial distribution of the average fuel solution temperature for each iterative calculation step.

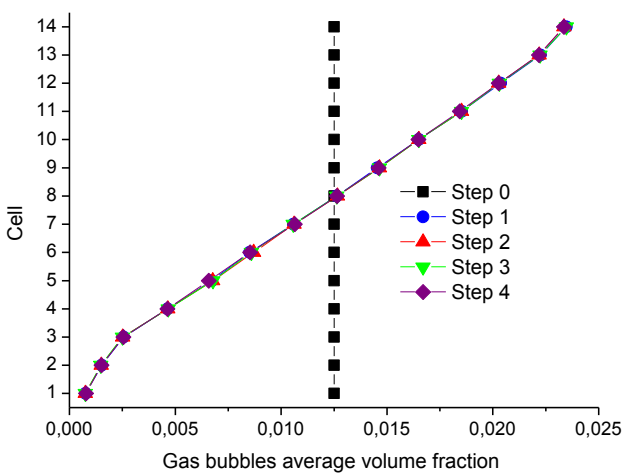

Figure 11. Axial distribution of the radiolytic gas volume fraction for each iterative calculation step.

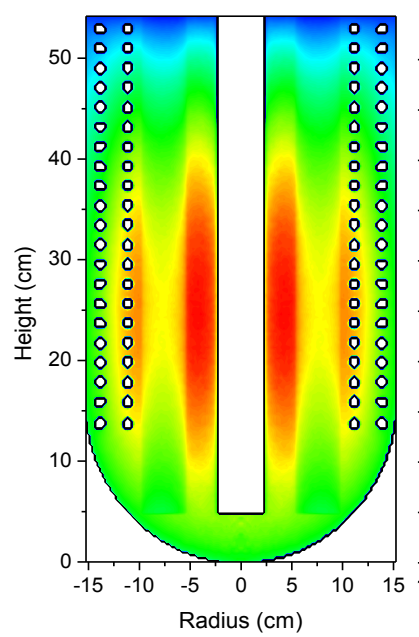

(a)

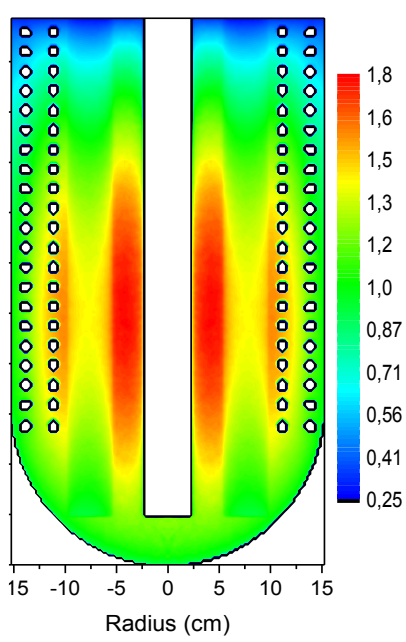

(b)
Figure 12. Fission induced energy deposition profile in the AHR conceptual design using the flux tally (F4) and the FMESH card. (a) With the multi-cell approach. (b) Without the multi-cell approach.

Further study, in Figure 13, shows the comparison between the two fission induced energy deposition profiles. The colorimetric scale used shows the relative differences in $\%$ (up to $5 \%$ difference) between the two profiles. As observed, the main differences are located in the upper and lower central area of the core. For the rest of the core, the observed differences are minimal or non-existent. This result is consistent with what has been obtained so far, bearing in mind that it is precisely in these areas where the parameters are furthest from the average behavior. 


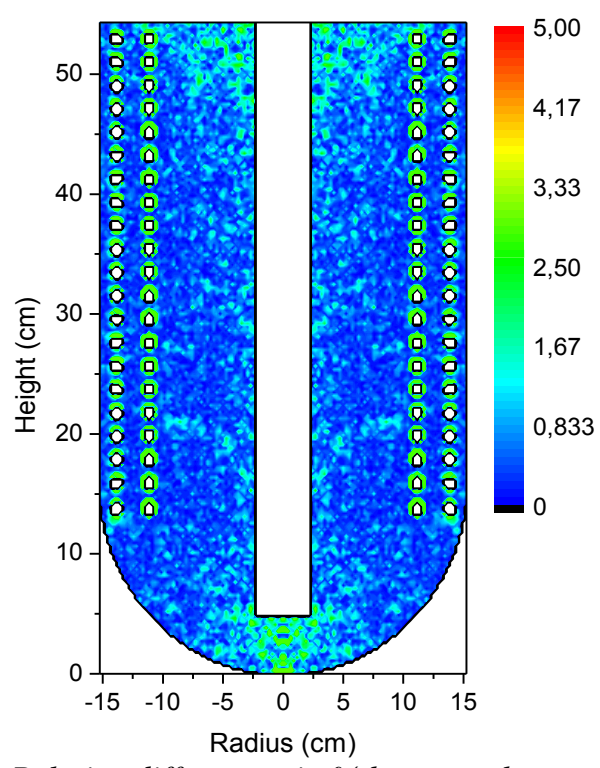

Figure 13. Relative differences in $\%$ between the two fission induced energy deposition profiles.

Although at the local level the variation of the main parameters of interest is appreciable, at the global level the variation is quite slight. The average fuel solution temperature and velocity, gas volume fraction and average radiolytic gas bubbles velocity values were $70.669{ }^{\circ} \mathrm{C}$, $0.0256 \mathrm{~m} / \mathrm{s}, \quad 1.236 \%$ and $0.1319 \mathrm{~m} / \mathrm{s}$, respectively. Consequently, these thermal-hydraulic parameters undergo a variation of $0.161{ }^{\circ} \mathrm{C}, 0.0009 \mathrm{~m} / \mathrm{s}, 0.015 \%$ and $0.0003 \mathrm{~m} / \mathrm{s}$ in comparison with the model without the multi-cell approach in [8]. In all cases, the relative differences, in comparison with the model without the multi-cell approach, are less than $3.4 \%$.

Figure 14 shows the volumetric distributions of the fuel solution temperature with and without the multi-cell approach. In Figure 15, it is shown the comparison between both volumetric distributions using the absolute differences between them.

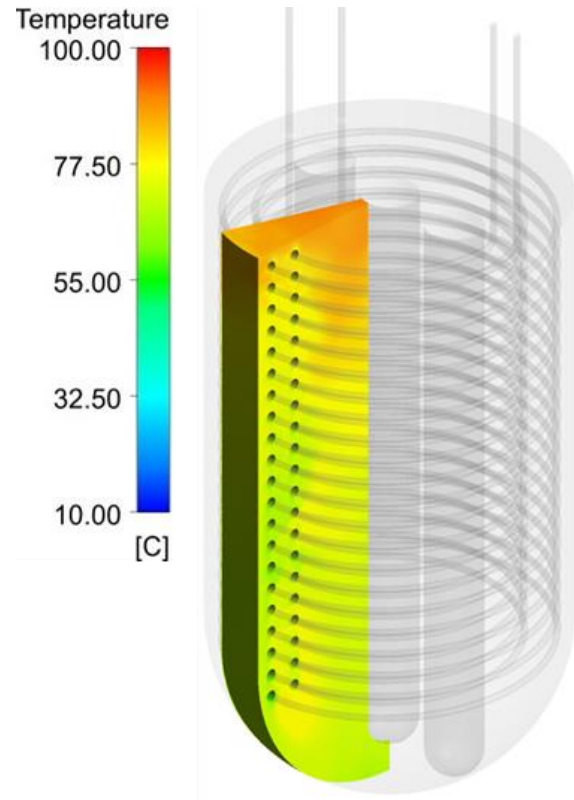

(a)

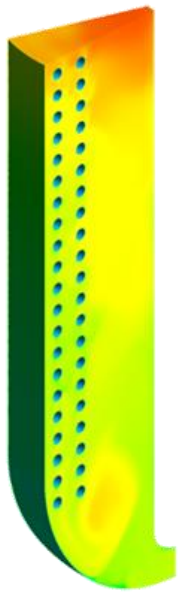

(b)
Figure 14. Volumetric distribution of the fuel solution temperature. (a) Without the multi-cell approach. (b) With the multi-cell approach.

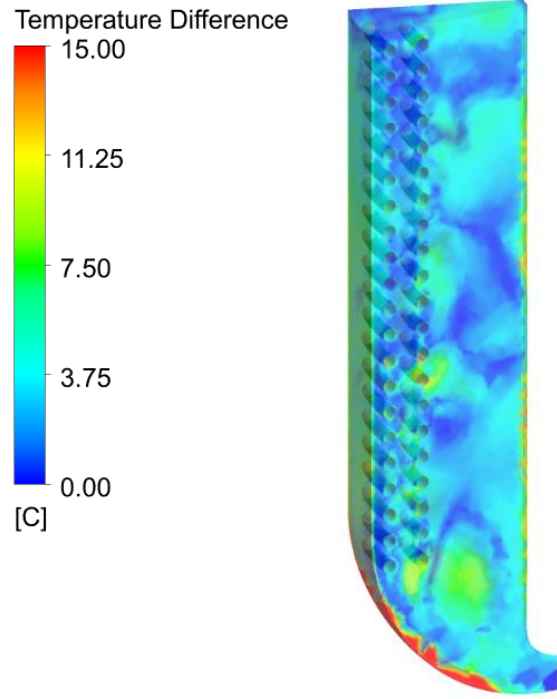

Figure 15. Absolute difference between the two volumetric distributions of the fuel solution temperature.

Figure 16 shows the comparison of the fuel solution temperature profile in the central YZ plane. As can be seen in these figures, the temperature distribution of the models is quite similar, with only slight differences in the upper and lower areas. As it was obtained for the model without the multi-cell approach, the spots with the highest temperatures are located in the upper zone and close to the central channel. This behavior is expected, considering that by natural convection the warmer fuel solution rises by density difference and the cooler fuel solution descends to replace it, generating a circular motion.

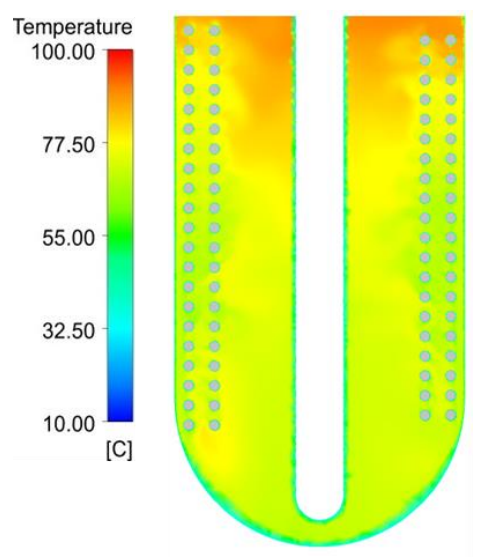

(a)

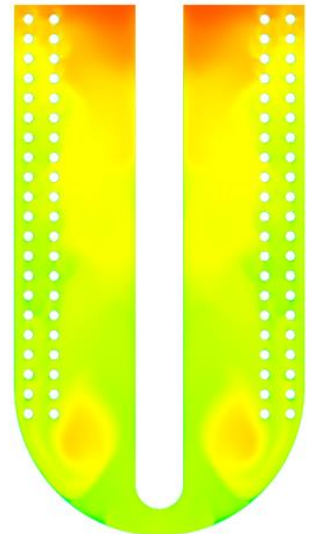

(b)
Figure 16. Fuel solution temperature profile in the central YZ plane. (a) Without the multi-cell approach. (b) With the multi-cell approach.

Figures 17 and 18 show the comparison between the fuel solution and radiolytic gas bubbles velocity profiles in the central YZ plane with and without the multi-cell approach, respectively. It is observed that although the global values are similar for the two models, there are significant differences in the profiles. The main difference is located in the lower area, where a significant deviation from the profile of the full AHR computational model is observed. This deviation from the expected profile is undoubtedly the result of the way the simplified geometry is represented in the model with the multi-cell approach. Despite this difference in the profiles, since the global and local velocity values agree with what was expected and 
obtained by the full AHR computational model, the results are considered acceptable.

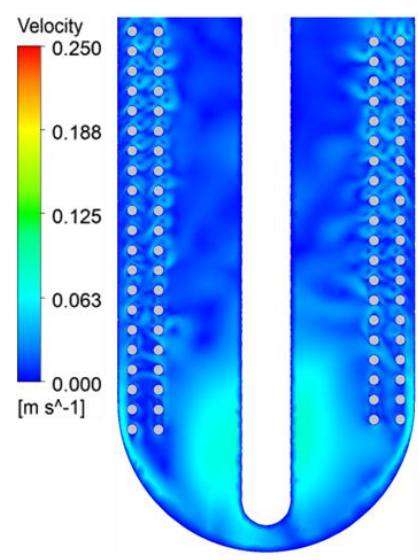

(a)

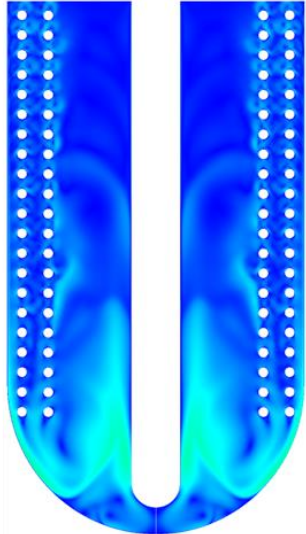

(b)
Figure 17. Velocity profiles of the fuel solution in the central YZ plane. (a) Without the multi-cell approach. (b) With the multi-cell approach.

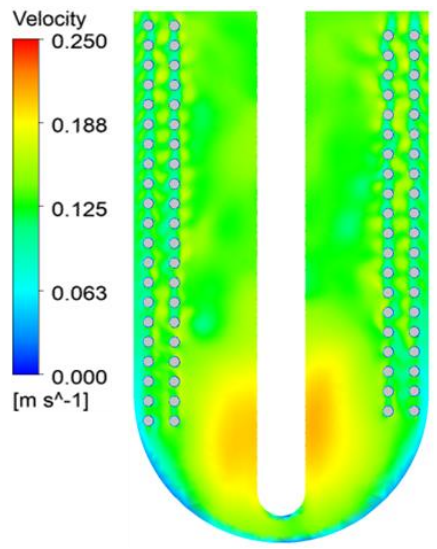

(a)

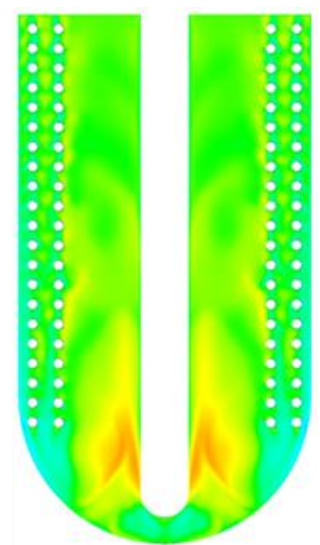

(b)
Figure 18. Velocity profiles of the radiolytic gas bubbles in the central YZ plane. (a) Without the multi-cell approach. (b) With the multi-cell approach.

Figures 19 and 20 show the comparison between the fuel solution and radiolytic gas bubbles streamlines with and without the multi-cell approach, respectively. The results obtained by the two models are very similar. In both models it can be seen how the fuel solution streamlines undergo recirculation in the lower area, with little movement in the upper area. While the radiolytic gas bubble streamlines experience no recirculation, being well linear and upward. The behavior observed in the fuel solution is as expected, considering the circular motion generated by natural convection (warmer fuel solution rises by density difference and the cooler fuel solution descends to replace). Another important issue to highlight is the significant differences between the average velocity values of the fuel solution and the radiolytic gas bubbles, the latter being five times higher.

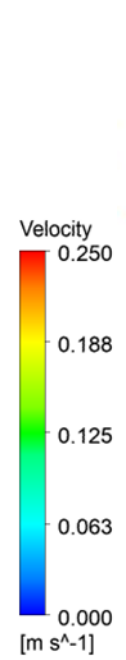

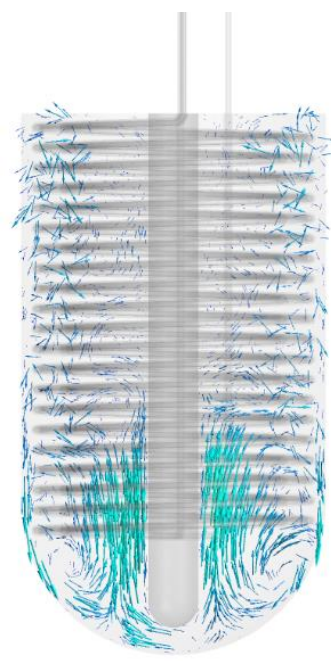

(a)

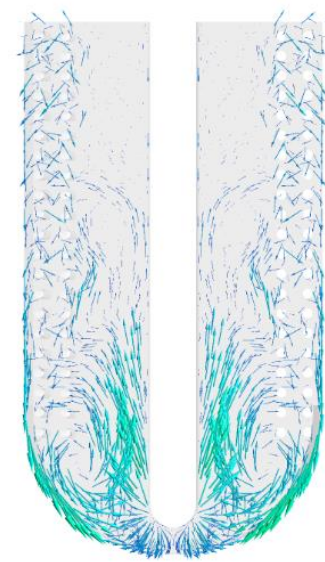

(b)
Figure 19. Fuel solution streamlines. (a) Without the multicell approach. (b) With the multi-cell approach.

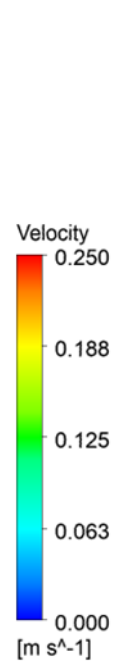

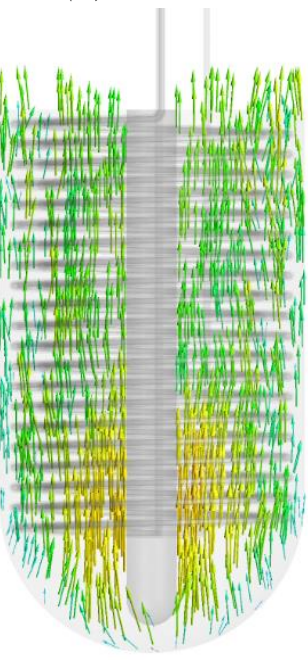

(a)

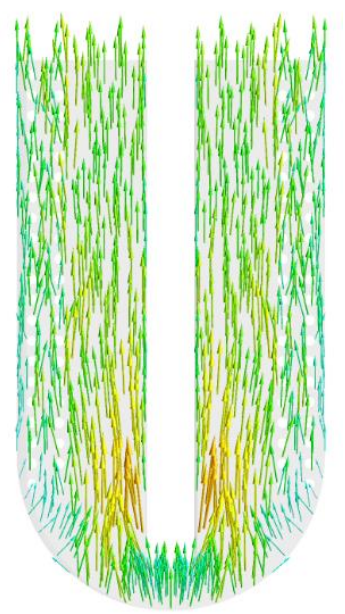

(b)
Figure 19. Fuel solution streamlines. (a) Without the multicell approach. (b) With the multi-cell approach.

Figure 21 shows the comparison between the volumetric distributions of the radiolytic gas volume fraction in the fuel solution with and without the multi-cell approach. Both models present similar results, it is observed how the radiolytic gas bubbles are consistently distributed, with the volumetric fraction in the upper zone being slightly higher from the upward movement of the bubbles. Figure 22 shows the absolute difference between the two volumetric distributions of the radiolytic gas volume fraction, as can be seen, the maximum absolute differences are found in the areas close to the pipes and central channel. 


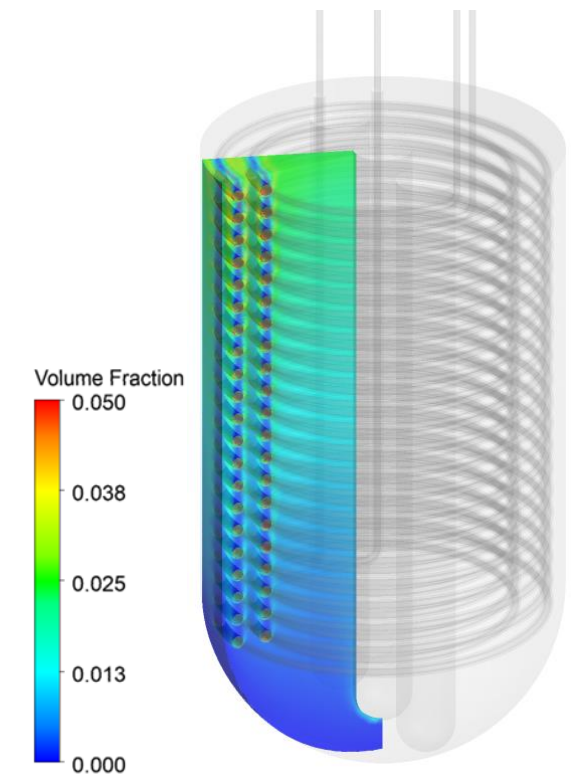

(a)

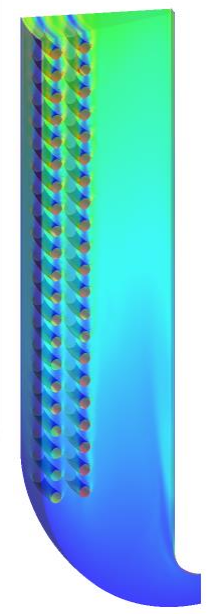

(b)
Figure 20. Volumetric distributions of the radiolytic gas volume fraction. (a) Without the multi-cell approach. (b) With the multi-cell approach.

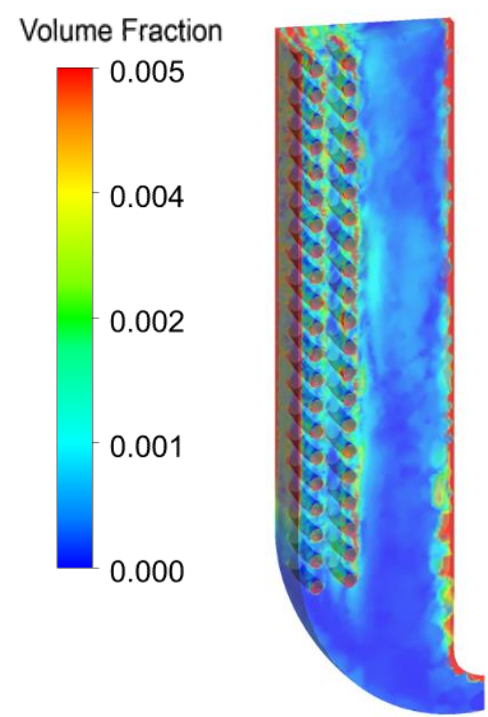

Figure 21. Comparison between the volumetric distributions of the radiolytic gas volume fraction in the fuel solution with and without the multi-cell approach.

\section{Conclusions}

In this work, the AHR computational model and coupling methodology presented in [8] were improved to include a multi-cell approach during the calculations. It was developed a simplified AHR computational model consisting of a $20^{\circ}$ section of the fuel solution. A number of initial simulations (without the multi-cell approach) were performed with this model, including a revisiting of the calculations performed in [8] with the full AHR computational model, which showed similar results. The simplified AHR computational model developed in this work allows relatively quick and computationally cheap calculations with the computation methodology in comparison with the full AHR computational model.

The main contribution of the changes made with the multi-cell approach was the capability to represent and study the influence of the axial density variation during the neutronic calculation with MCNP code and the subsequent feedback to the thermal-hydraulic code. It was found that the addition of the multi-cell approach to the original model cause a small change to the overall reactor behavior. Thermal-hydraulic parameters such as, average fuel solution temperature and velocity, gas volume fraction and average radiolytic gas bubbles velocity undergo a variation of $0.161{ }^{\circ} \mathrm{C}, \quad 0.0009 \mathrm{~m} / \mathrm{s}, \quad 0.015 \%$ and $0.0003 \mathrm{~m} / \mathrm{s}$, respectively, in comparison with the model without the multi-cell approach. In contrast, local differences were obtained mainly for the fuel solution temperature and radiolytic gas bubbles volume fraction. These local differences are the result of the way the simplified geometry is represented in the model with the multi-cell approach.

\section{Acknowledgements:}

This research was partially supported by the National Council for Scientific and Technological Development (CNPq), project no: 141270/2016-0, the Coordination for the Improvement of Higher Education Personnel (CAPES), project no: 88887.518186/2020-00, the Research Support Foundation of the State of Pernambuco (FACEPE), project number: BFP-0093-3.09/21 and the Brazilian National Nuclear Energy Commission (CNEN), project no: 01341.011318/2021-51.

$\begin{array}{ll}\text { Nomenclature } \\ \text { AHR } & \text { Aqueous Homogeneous Reactor } \\ \text { LEU } & \text { Low Enriched Uranium } \\ \text { HEU } & \text { Highly Enriched Uranium } \\ \text { NRU } & \text { National Research Universal } \\ \text { HFR } & \text { High Flux Reactor } \\ \text { UFPE- } & \text { Reactor Engineering Group of the Nuclear Energy } \\ \text { DEN-GER } & \text { Department of the Federal University of Pernambuco }\end{array}$

\section{References:}

[1] NEA, "The Supply of Medical Radioisotopes 2015 Medical Isotope Supply Review: 99 Mo/99m Tc Market Demand and Production Capacity Projection 2015-2020," Paris, 2015.

[2] NEA, "The Supply of Medical Radioisotopes 2018 Medical Isotope Demand and Capacity Projection for the 2018-2023 Period," Paris, 2018.

[3] NEA, "The Supply of Medical Radioisotopes. 2019 Medical Isotope Demand and Capacity Projection for the 2019-2024 Period," 2019.

[4] NEA, "The Supply of Medical Radioisotopes: Review of Potential Molybdenum-99 / Technetium-99m Production Technologies," Paris, 2010.

[5] IAEA, "Homogeneous Aqueous Solution Nuclear Reactors for the Production of Mo-99 and other Short Lived Radioistotopes,' Vienna, 2008

[6] IAEA, "Research Reactor Database (RRDB)," 2021. [Online]. Available:

https://nucleus.iaea.org/RRDB/RR/ReactorSearch.aspx?filter=0. [Accessed: 03-Mar-2021].

[7] D. M. Pérez, "Projeto e análise neutrônico-termoidráulica de um reator homogêneo aquoso usando combustível de baixo enriquecimento para a produção de radioisótopos usados na medicina," Doctoral Thesis, Universidad Federal de Pernambuco, Recife, Brasil, 2020.

[8] D. M. Pérez, D. M. Pérez, L. H. Pardo, D. E. M. Lorenzo, and C. A B. de Oliveira Lira, "Multi-physics evaluation of the steady-state operation of an Aqueous Homogeneous Reactor for producing Mo99 for the Brazilian demand," Int. J. Thermodyn., vol. 24, no. 1, pp. 9-22, Feb. 2021.

[9] Los Alamos National Laboratory, "MCNP6.1/MCNP5/MCNPX User Manual," Los Alamos National Laboratory, Los Alamos, 2013.

[10] ANSYS Team, “ANSYS CFD 19.0 Documentation, User's Guide manual," 2019. [Online]. Available: http://www.ansys.com. [Accessed: 01-Jul-2019].

[11] D. M. Pérez et al., "Thermal-Hydraulics Study of a 75 kWth Aqueous Homogeneous Reactor for 99 Mo Production," $J$. Thermodyn., vol. 2015, pp. 1-11, 2015.

[12] D. M. Pérez, D. E. M. Lorenzo, C. A. B. De Oliveira Lira, C. R. G. Hernández, M. C. Rodríguez, and L. P. R. Garcia, "Effects of some 
calculation parameters on the computational modelling of temperature, velocity and gas volume fraction during steady-state operation of an aqueous homogeneous reactor," Int. J. Nucl. Energy Sci. Technol, vol. 11, no. 1, p. 1, 2017.

[13] D. M. Pérez, D. E. M. Lorenzo, C. A. B. de Oliveira Lira, and L. P. R. Garcia, "Neutronic evaluation of the steady-state operation of a $20 \mathrm{kWth}$ Aqueous Homogeneous Reactor for Mo-99 production," Ann. Nucl. Energy, vol. 128, 2019.
[14] L. H. Pardo, D. M. Pérez, D. M. Pérez, D. E. Milian Lorenzo, and C. A. Brayner de Oliveira Lira, "Coupled multi-physics simulation for the evaluation of an accelerator-driven Aqueous Homogeneous Subcritical System for medical isotope production," Prog. Nucl. Energy, vol. 134, p. 103692, Apr. 2021.

[15] D. M. Pérez et al., "Study of radiolytic gas bubbles formation and behaviour in an aqueous uranyl sulphate solution using ImageJ," Int. J. Nucl. Energy Sci. Technol., vol. 14, no. 3, pp. 235-251, 2020. 